\title{
Simulation of production processes with Plant Simulation
}

\author{
M. MiLTÉNYI, L. CZÉGÉ \\ University of Debrecen, Faculty of Engineering, Department of Mechanical Engineering, Specialized in \\ Automotive Process Designer, Dual student of Robert Bosch Automotive Steering Kft, miltenyim@gmail.com
}

Abstract: This article presents the modelling of interconnected companies' logistic processes with Tecnomatix Plant Simulation by Siemens. It has two main parts. The first contains the details of recognition including simulation. The second part presents the modelling with Tecnomatix Plant Simulation. My publication is supported by the EFOP3.6.1-16-2016-00022 project. The project is co-financed by the European Union and the European Social Fund.

Keywords: modelling, simulation, Plant Simulation, supply chain

\section{Introduction}

The first industrial revolution began in the 18th century with the use of steam energy. The second took place in the 19th century, when conveyor belts have been used in the industry. The third industrial revolution began in the 1970s when computerized partial automation created for production.

Nowadays, at the time of the industry 4.0, the goal is to maximize the utilization of production lines and eliminate losses. Simulating processes are essential to examine and reach these targets. Simulation is when an existing or fictive system is modelled by using a program. The elements of the created model and its properties are similar to the original system, which they were created from. The aim of the simulation can be to simplify transparency, process analysis, develop them, or create new elements.

\section{Recognition}

Recognition is to acquire the knowledge or its process. Getting to know the model, opens up many opportunities for us. Optimizing existing elements, creating new ones, and even connecting new and old elements. [1]

\subsection{The types of recognition}

I separated recognition into three main groups. They have different advantages and disadvantages depending on their usages. Price, time and reliability are the most important factors. 


\subsubsection{Experimentation}

Recognition can be experimentation, what they perform on a physical model. Its disadvantage is that it is costly and necessary to have a finished physical model, so it is often impossible.

\subsubsection{Analysis}

Recognition may even be an analysis, where mathematical relationships are used. Its disadvantage is its complexity. The results are faster, however the uncertainties are common. In the analytical solution, the results are obtained by solving a formula.

\subsubsection{Simulation}

Simulation is also a form of recognition. It should not be confused with a simple animation. Simulation always controlled by events. The goal is to copy elements in every case, regardless it is a real or a fictive model. Its preparation cannot be called simple, but the finished results are the most transparent, formattable, and modifiable.

Even in antiquity, the generals tried to derive the reaction of their enemies. They could simulate battles based on their thoughts.

However, in computing the start of applying the simulation was at the time of the World War II, when they tried to simulate the trajectory of the bullets depending on different effects, such as wind or rain.

\subsection{When and why we use simulation}

The complex processes are frequent at producing companies. According to the lean philosophy, whether it is a production line, logistics or any form of material flow, the discovery and elimination of losses is essential for any company. For the operation of the Kaizen, simulation is the best to introduce continuous improvements. Optimizations and "What if?" ideas are also easy to test with this method. Simulation requires the existence of appropriate program, information about the model and its properties. The exact knowledge of the program is also essential.

There are many software to simulate production processes, for example Process Simulator by ProModel, Flexsim, SimCad or Tecnomatix Plant Simulation by Siemens.

\section{TECNOMATIX PLANT SIMULATION}

Tecnomatix Plant Simulation is an event-controlled simulation program, which is suitable for designing material flows in 2D or 3D environments. There are many built-in modules, which can be used to create, develop, and modify complete production lines or simulate entire companies.

\subsection{Design surface}

We work on the simulation area. The blocks of the model simply can be pull out of the toolbar. You can change their properties if double click on elements. The model tree shows all the tools you have already used. The console writes the information and messages to the user. 


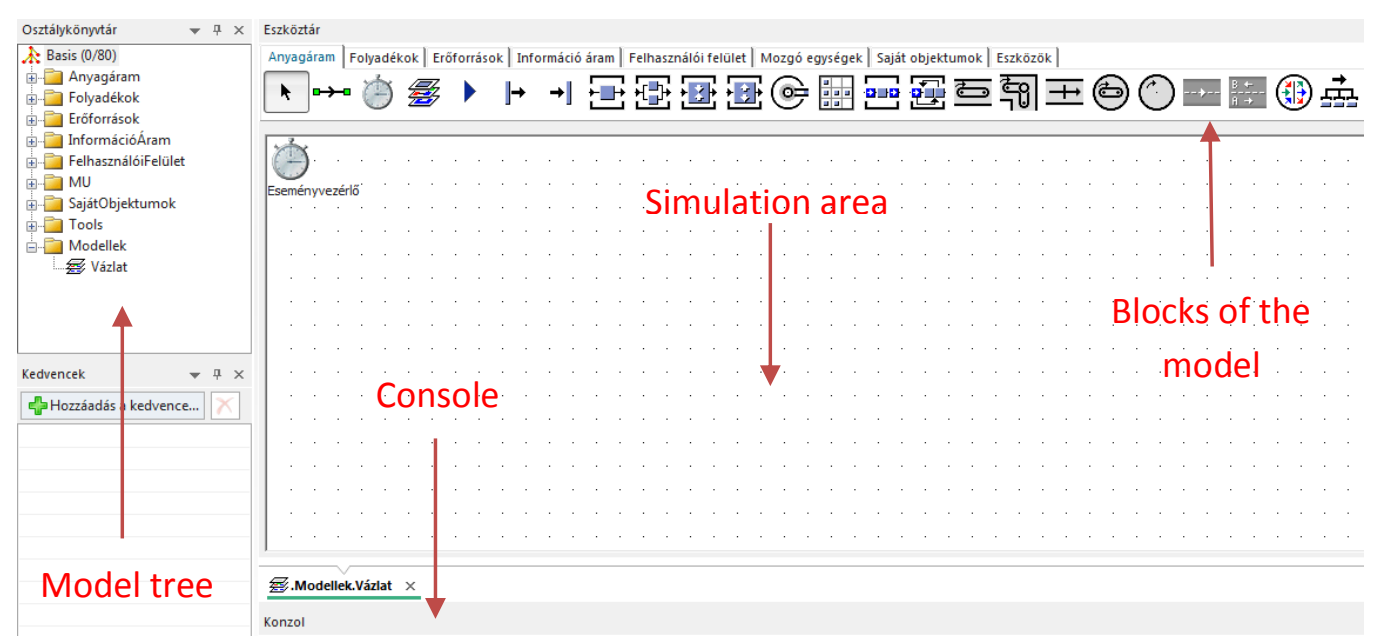

Figure 1. Design surface at Plant Simulation.

\subsection{My work - Bear Game}

I simulated the well know Beer Game. In this case, the task of the simulation is a supply chain modelling, where we deliver beer from a brewery to the consumer. It is a board game and we control one of the industrial company. There are four different station, Retailer, Wholesaler, Distributor and Factory.

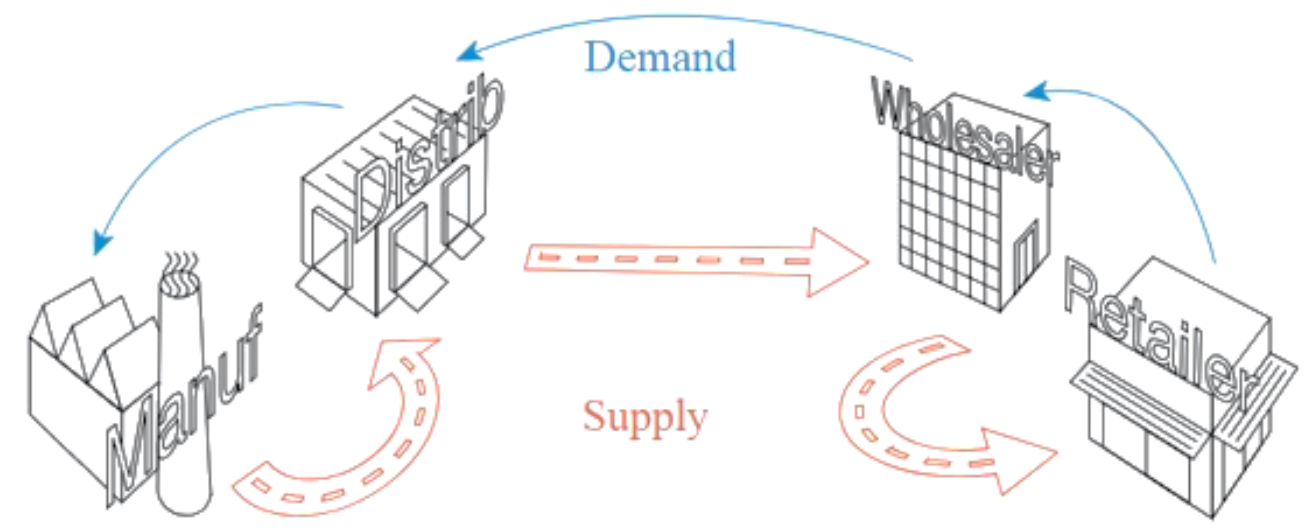

Figure 2. Beer game structural setup [2]

The game plays in rounds, what simulates weeks. The orders come every week, but the delivery has 2 weeks delay.

Players have to carry out the following steps in each round:

- Receive incoming orders

- Receive incoming delivers

- Send out deliveries

- Decide the quantity of the order 


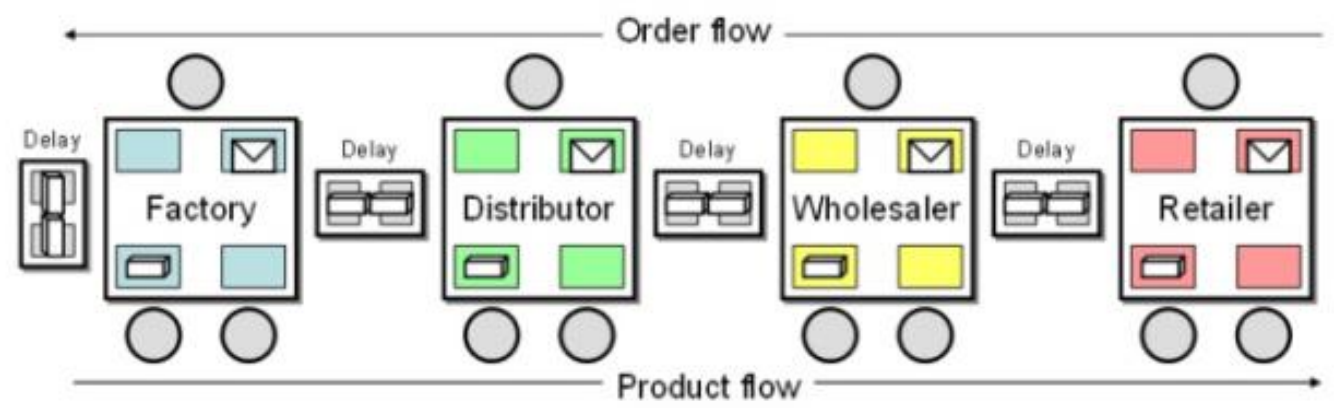

Figure 3. Beer game structural setup. [3]

\subsection{My work - Bear Game}

My model was created in a 2D environment. In each case, a dialog box pops up to request ordering information. Every player only knows the order of the previous station, which appears on the console, they are not aware of how much the other companies or the buyer ordered.

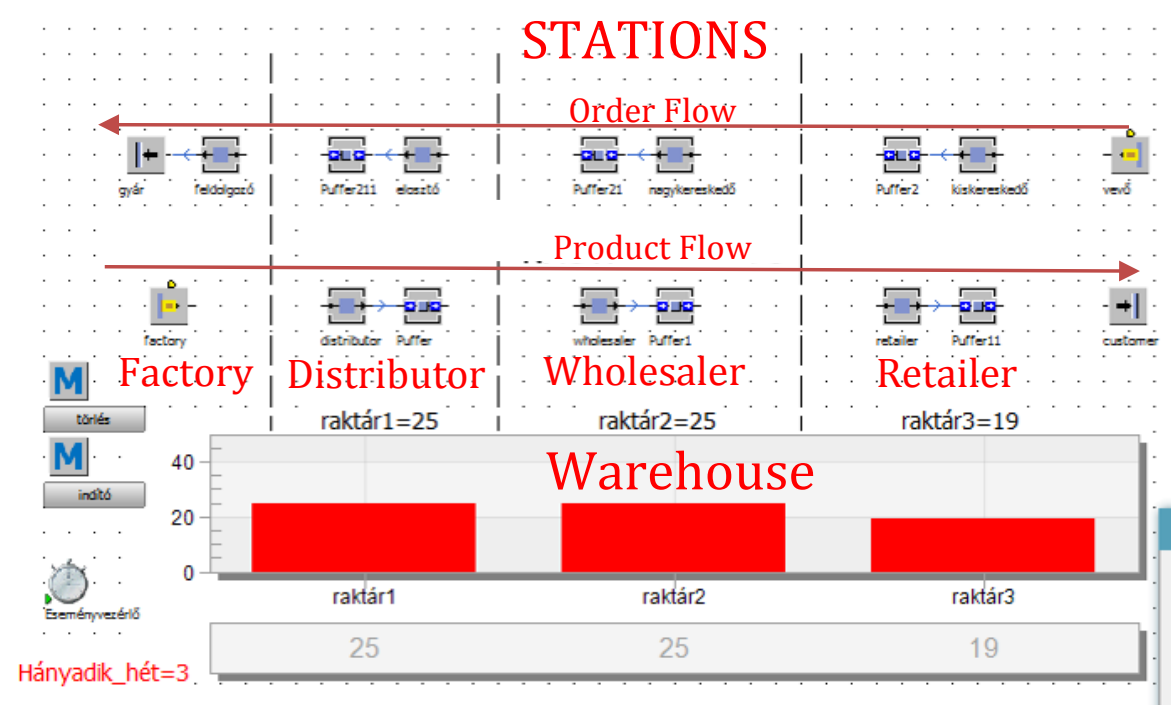

Figure 4. My own simulation.

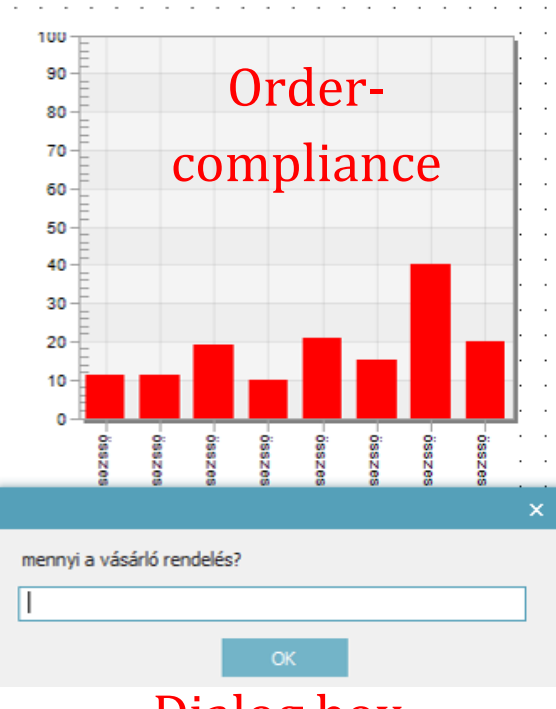

Dialog box

\subsubsection{Stations}

I separated four stations, the Retailer, the Wholesaler, the Distributor and the Factory. At the order flow, the players send their demands. The stations could decide that, they want to order the product or send that from their warehouses. The goal is to have the lowest amount of stock, order the least and satisfy the demands.

At the order flow the stations are "Single Procs" objects, what only can do one process. In our case, it accepts orders. The Customer is a "Source" object, what creates the units (the orders), and the Factory is a "Drain" object, it destroys the units at the end of the flow.

The product flow differs from the order flow in that the Customer is a "Drain" and the Factory is a "Source" object. The Factory produces the units (the beers), and the Customer process them. The stations are still "Single Procs" objects, they only have one task, now it is that to send the products. 


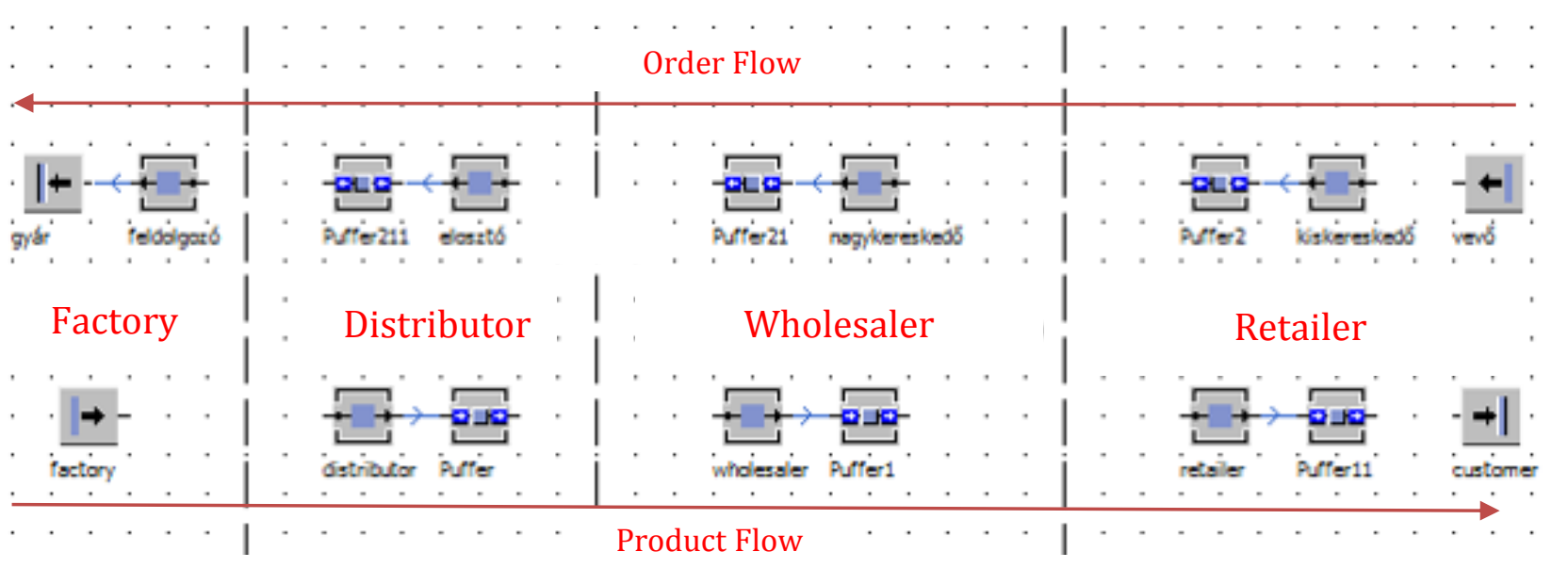

Figure 5. Stations.

\subsubsection{Methods}

Programming is essential in Plant Simulation for managing complex tasks. Tecnomatix own programming language is Simtalk. The methods are the area where you can write your program. Each method means writing a separate program. For example, each station has a "prompt" method that request the number of orders with dialog box.

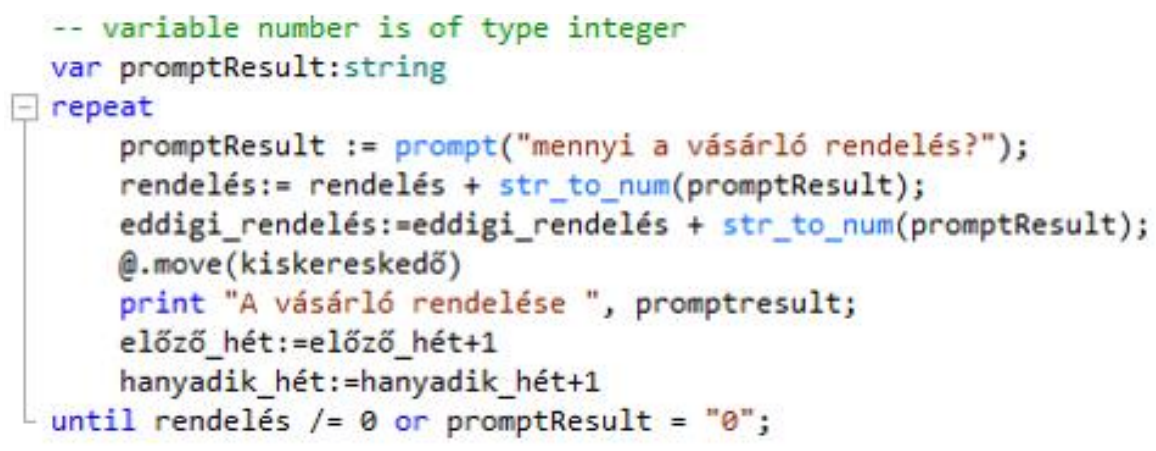

Figure 6. Prompt method.

Every station has a sensor, which detect the contact with them. If a sensor get a signal, their method would start. The user could decide whether, he wants an "exit" or an "entrance strategy". If he want that, the methods start when units left the stations, then he needs an exit strategy, otherwise if he want to start methods when units enter, then he needs an entrance strategy. That means, he could add the method at the controls properties of the station.

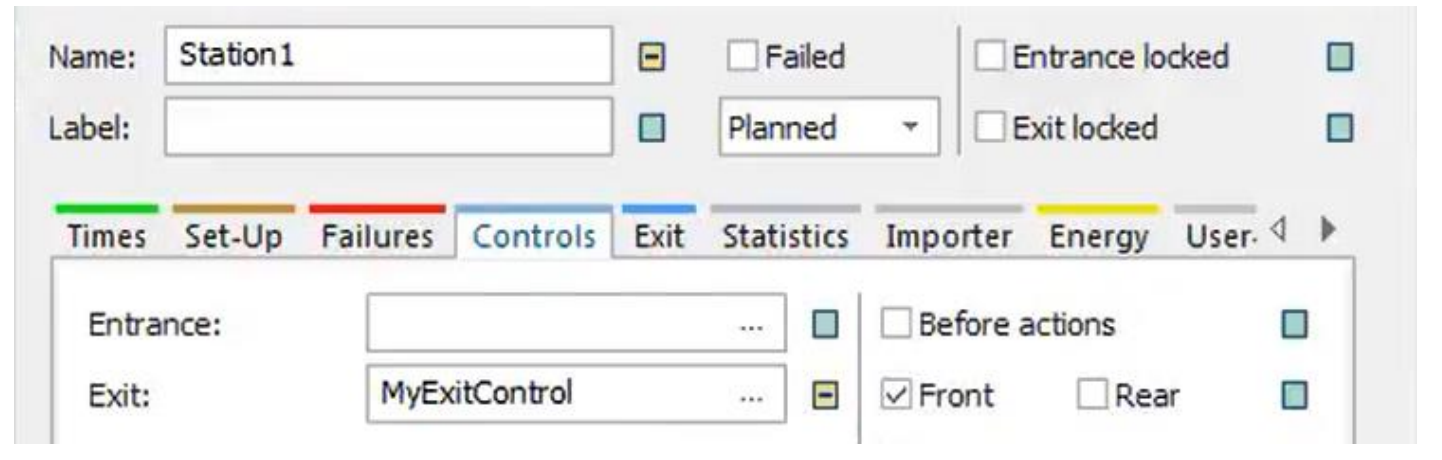

Figure 7. Exit control. 


\subsection{Possibilities for development}

Based on the finished model, there are several possibilities for development.

Possible to create an offer for the user, about the amount of the order, indicate if stocks are starting to run out or the whole process can be automatic. It would work optimally without human decisions.

Possible to create the simulation at 3D environment, representing the companies, the workers and the means of transport.

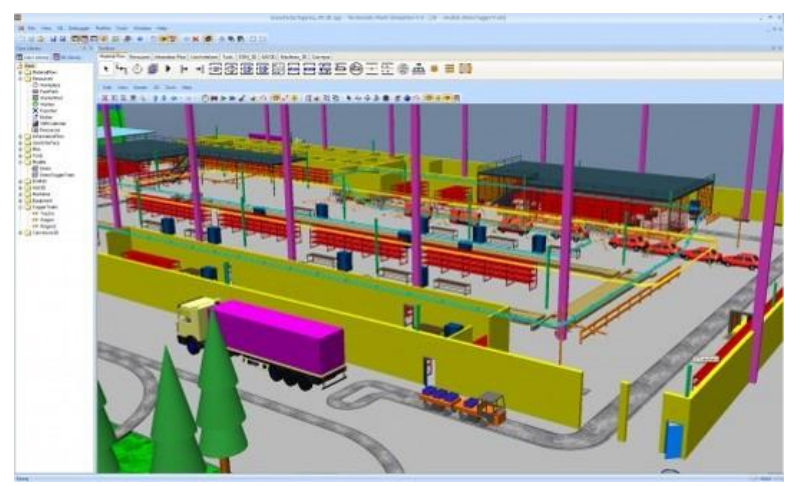

Figure 8. 3D designing. [4]

\section{Summery}

I started my research about simulation of production processes in early 2019. It took me about two months to get to know Tecnomatix Plant Simulation. The books, "Manufacturing Simulation with Plant Simulation and Simtalk" [5] and "Tecnomatix Plant Simulation" [6] by Steffen Bangsow was a great help in this.

I got the idea of the simulation at the university, where we played the Beer Game. I wanted to create a transparent simulation about it. The result is that it succeeded.

My simulation can use by other companies, where there is a problem with managing stocks, orders, and supply chains. It may be useful for cost reduction. Also usable at the education, where process engineer student could use for their studies.

\section{Anknowledgment}

Publication is supported by the EFOP-3.6.1-16-2016-00022 project. The project is co-financed by the European Union and the European Social Fund.

\section{References}

[1] Gy. Lipovszki (2017) Szimuláció. Budapesti Műszaki Egyetem, Mechatronika, Optika és Gépészeti Informatikai Tanszék.

[2] MA-SYSTEM, Bear game, online game, beergame.masystem.se, download: 26 May 2019 
International Journal of Engineering and Management Sciences (IJEMS) Vol. 4. (2019). No. 4 DOI: 10.21791/IJEMS.2019.4.2.

[3] Beer game, Structural setup, Beergame.org, download: 27 June 2019

[4] Graphic Speak, Free student edition, Gfxspeak.com, download: 27 June 2019

[5] B. Steffen (2010) Manufacturing Simulation with Plant Simulation and Simtalk. Springer International Publishing, Switzerland.

[6] B. Steffen (2015) Tecnomatix Plant Simulation. Springer International Publishing, Switzerland. 